\title{
What is Radiology? A look into the history, advancement and modern applications of the specialty
}

\author{
Hassan I. Osman, MBBS ${ }^{\text {a,b,c,d }}$, Maisa Badreldeen, MD, MS ${ }^{\mathrm{e} *}$ \\ ${ }^{\mathrm{a}}$ hassan.io@live.co.uk \\ ${ }^{a}$ Department of Psychiatry, Napata College, Khartoum, Khartoum,Sudan \\ ${ }^{\mathrm{b}}$ Napata Research and Innovation Center (NRIC), Napata College, Khartoum, Khartoum, Sudan \\ 'Department of General Surgery, Abdelwahhab Basheer Unit, Ribat University Hospital (RUH), Khartoum, Khartoum, Sudan \\ ${ }^{\mathrm{d}}$ Reviewer, Internation Journal of Research Publications (IJRP) \\ ${ }^{\text {e}}$ Department of Radiology, Napata College, Khartoum, Khartoum ,Sudan
}

\begin{abstract}
Introduction: Nowadays, it is virtually to imagine a hospital functioning without a radiology department fitted with the latest machines and equipment science has to offer as well as at least one radiologist sitting in a dark room staring at a computer screen and carefully analyzing the image in front of them. However, a few centuries ago, that was the reality with which physicians had to deal. Today, medical imaging, as it has become referred to, is an essential and integral part of the practice of medicine. Problem Statement/Rationale: Whilst contemplating writing this paper, we were taken aback when we came across a total of 0 articles covering the topic in a similar manner. Ergo, we decided it only be appropriate to take it upon ourselves to change that occurrence. Objectives: General: To shine light upon the beautiful combination of sciences that is radiology Specific: 1) To start an initiative in which information like that illustrated below is accessible. Research methodology: The following steps took place:1) The idea was formulated. 2) The technologies comprising radiology were categorized by experts. 3) Each of the technologies was searched using all available databases (Google Scholar, PubMed, Medline, etc.) 4) The findings were collected and are illustrated below.
\end{abstract}

Radiology; Napata College; History of Radiology; Medical History

\section{Main text}

Introduction:

The science of radiology first came to be through the work of WC Röentgen (1845-1923) ${ }^{[1]}$. In this paper, we aim to see to it that the science receives the recognition it deserves.

Problem Statement/Rationale:

Whilst contemplating writing this paper, we were taken aback when we came across a total of 0 articles covering the topic in a similar manner. Ergo, we decided it only be appropriate to take it upon ourselves to change that occurrence. 


\section{Objectives:}

General: To shine light upon the beautiful combination of sciences that is radiology

Specific:

1) To start an initiative in which information like that illustrated below is accessible

Research methodology:

The following steps took place:

1) The idea was formulated

2) The technologies comprising radiology were categorized by experts

3) Each of the technologies was searched using all available databases (Google Scholar, PubMed,

Medline, etc.)

4) The findings were collected and are illustrated below.

Ethical considerations:

\section{The authors hereby declare no conflicts of interest}

Who was WC Röentgen?

'The scientist must consider the possibility, which usually amounts to a certainty, that his work will be superseded by others within a relatively short time, that his methods will be improved upon and that the new results will be more accurate and the memory of his life and work will gradually disappear.' [1]

'pride in one's profession is demanded, but not professional conceit, snobbery, or academic arrogance, all of which grow from false egoism.' [2]

- WC Röentgen, 1894

Born to Friedrich and Charlotte Röentgen in 1845 Rhineland (Germany), Wilhelm was immediately provided with an opportunity to take on life and all the obstacles it inevitably manifests, as his parents were from a rather well-known family of merchants (they were cousins) ${ }^{[1]}$. When little Wilhelm was 3, his family moved to the Netherlands where he'd, at 16 years old, attend Utrecht Technical School only to pull a prank so extreme he managed to get expelled (it is unclear what the nature of the prank was), Wilhelm would then move to Zurich to attend the Polytechnic School ${ }^{[1]}$; an institution from which Wilhelm would graduate in 1868 with a diploma in engineering.

A year later Wilhelm Röentgen, would become Dr. Wilhelm Röentgen (hereafter referred to WC Röentgen, Professor Röentgen or Dr. Röentgen), Dr. Röentgen's PhD was awarded for his studies on the properties of gases ${ }^{[1]}$. This was done under the direction of Professor AEE Kundt who would, in 1870, move to the University of Würzburg where Dr. Röentgen would accompany as an assistant. In 1872, Dr. Röentgen would get married to Anna Ludwig (1839-1919) with whom he had a happy marriage. Again, Dr. Röentgen would accompany Professor Kundt, this time to Strasbourg where, in 1876, Röentgen was appointed associate professor in theoretical physics ${ }^{[1]}$. 
3 years later, in 1879, Dr. Röentgen would be appointed Professor of physics at Giessen ${ }^{[1]}$ (Germany). In 1888, Professor Röentgen would move back to the University of Würzburg, where in 1894, Professor Röentgen would be elected to the office of the rectorship of the University ${ }^{[1]}$.

Although this would have been a rather remarkable career and would have definitely landed Professor Röentgen 'on the history books'. However, the discovery that would rise Professor Röentgen has yet to manifest itself. In 1895, Professor Röentgen first observed a phenomenon he labelled as ' $\mathrm{x}$-rays' ${ }^{[1]}$. This phenomenon would take the world by storm, as illustrated by the following quote from the Vienna Presse: 'A Photographic Discovery: From our own correspondent: Vienna. Monday night. A very important scientific discovery has recently been made by Professor Röentgen of Würzburg University, the details of which have already reached Vienna, and are now being carefully examined by several scientific authorities here. Professor Röentgen used the light emitted from one of Crookes' vacuum tubes, through which an electric current is passed to act upon an ordinary photographic plate.

The invisible light rays, of whose existence there is already ample evidence, then show this peculiarity; that to them wood and other organic substances are transparent, whilst metal and bones, both human and animal alike, are opaque to those rays. That is to say, they will for instance absorb the rays which have passed through a wooden case in which bones or metals may be enclosed. Thus it is possible to photograph in the manner described any bones or metals which may be contained in wooden or woolen coverings. Moreover, as human flesh, being organic matter, acts in the same way as such coverings towards the invisible rays from a Crookes' vacuum tube, it has become possible to photograph the bones - say — of a human hand, without the flesh appearing on the plate. There are photographs of this description already in Vienna. They show the bones of the hand, together with the rings that were worn on the fingers, metals, as I remarked above being opaque to these x rays - but they show nothing else. They are ghastly enough in appearance, but from a scientific point of view, they open up a wide field for speculation. Among the practical uses of the new discovery it is stated that it will henceforth be possible for surgeons to determine by help of this new branch of photography, the exact position of any bullet that may be embedded in the human body or, again, to render visible any fractures there may be in the bones prior to performing any operation on the respective part of the body. And there are various other uses to which the new method may be put, as for example, in connection with caries and other bone diseases. The Presse assures its readers that there is no joke or humbug in the matter. It is a serious discovery by a serious German professor.'

To us, in 2021, the following quotes from the above excerpt are rather remarkable since they show how far we have come in a few centuries' time:

'The invisible light rays, of whose existence there is already ample evidence,'

'The Presse assures its readers that there is no joke or humbug in the matter. It is a serious discovery by a serious German professor.'

This historical point in time marks, as far as we can tell, the birth of radiology. Here's the beautiful manner in which Alexi Assmus ${ }^{[2]}$ articulated the events:

'Roentgen turned to a new interest in October of 1895: the study of cathode rays. In the course of repeating the experiments of Hertz and Lenard, he happened to notice a glowing fluorescent screen set off quite some distance from the Crookes' tube he was operating. The screen sat much farther away than the six to eight centimeters that Lenard had found to be the maximum distance for which cathode rays maintain their power to induce fluorescence. Roentgen recognized the effect as worthy of his undivided attention and devoted the next six weeks to its uninterrupted study. 
Three days before Christmas [of 1895] he [referring to Professor Röentgen] brought his wife into his laboratory, and they emerged with a photograph of the bones in her hand and of

the ring on her finger. The Würzburg Physico-Medical Society was the first to hear of the new rays that could penetrate the body and photograph its bones. Roentgen delivered the news on the 28th of December $1895 \ldots . .$.

On the 13th of January [of 1896], Roentgen presented himself to the Kaiser and was awarded the Prussian

Order of the Crown, Second Class. And on the 16th of January the The New-York Times announced the discovery as a new form of photography, which revealed hidden solids, penetrated wood, paper, and flesh, and exposed the bones of the human frame.' ${ }^{[2]}$

So, what was Professor Röentgen like? According to Professor PM Dunn of the University of Bristol:

'Röentgen was a tall, dark, slender man (fig 1). He was a very honest straightforward investigator, a fine experimentalist, and an outstanding teacher. A modest man, he was meticulously tidy and took the greatest care of his apparatus. He was a scientist who lived for science.' ${ }^{[1]}$

According to Professor Graham:

'He conceived clearly the problem he proposed to tackle, experimented skillfully and ingeniously, rigidly controlled and tested his results, and presented them precisely and logically with a remarkable economy of words.' $[1,3]$

We believe the following to be a beautiful articulation of the character of Professor Röentgen:

'He disliked publicity and steadfastly declined to have his rays named eponymously or to accept any of the many offers made to commercialise his discovery. Many honours came to him. He received an honorary degree of MD from the University of Würzburg, the Rumford Gold Medal of the Royal Society, and also the Gold Medal of the Franklin Institute of Philadelphia. In 1901 he was one of the first recipients of the Nobel Prize, worth 50000 Swedish kroner. He passed the whole sum on to his university to promote scientific study.'

Following all of this, in 1900, Professor Röentgen moved to Munich where he was the Director of the new Physical Institute. In 1919, his wife Anna had passed away following a long battle with ill-health ${ }^{[1]}{ }^{1}$ year later, now aged 75, Professor Röentgen was elected Professor Emeritus. 3 years later, in 1923, Professor Röentgen would lose his battle with cancer. He was $78^{[1]}$.

What was the situation like prior to Röentgen?"

We do know that it has been millennia since the Greeks hypothesized the notion of the atom being the central building block of all matter ${ }^{[4]}$. Research into the 'elementary particle of electricity' become more commonplace following the establishment of Faraday's laws ${ }^{[4]}$. Also markedly remarkable were the participations of Geissler, Plücker, Hittorf, Lenard, Goldstein, Crooke, Hertz, Thomson and Stoney in advancing our understanding. It is through the combined efforts of all the aforementioned individuals, as well as numerous unmentioned individuals, that we were able to reach the point we reached. As per Nüsslin: 
'the progress in X-ray technologies was the result of the engagement of many physicists and engineers who also stimulated the establishment of new professional societies. ${ }^{[4]}$

The history of radiology:

Now, we shall be discussing the historical aspect of the wonderful science that is radiology. As aforementioned, the art came to be through the unfathomably innovative efforts of Professor Röentgen. Of course, no mention of radiology is complete without our paying tribute to the giants, leaders and pioneers who were unaware of the devastating effects radiation can have on the human body. As per Nüsslin:

'It is a tragedy that scientists, practitioners, technical and medical staff fascinated by the potential of the new radiation were not aware the radiation hazards - mostly not known or explored yet -and ignored proper radiation protection measures........... A cenotaph in Hamburg commemorates the hundreds of pioneers who ultimately died from the exposure of X-rays in radiology. ${ }^{[4]}$

Exploring radiological technologies:

Computed Tomography:

Radiologists interpret the findings displayed in the images created by certain machines. One of those would be computed tomography, which was first conceptualized in 1938 by Frank, but only became manifest physically in 1972 by Hounsfield ${ }^{[4,5]}$. Given how they have become an integral part of the operation of integral systems, it is unfathomable to us to imagine that the so-called 'slip-ring' scanners only became available in $1987^{[5]}$. Furthermore, up and until this point in time, as per Kalender:

'Although dynamic CT was well established and the need for the shortest possible scan time was evident, volume scanning had not yet been considered.' ${ }^{[5]}$

Not only that, but it wasn't until 1992 that spiral scanning was generally accepted by professionals ${ }^{[5]}$. Furthermore, Multi-slice spiral scanning only became available in $1998^{[6]}$. So, how do CT scans occur? According to Kalender:

'X-ray computed tomography consists of measuring attenuation profiles of a transverse slice of a patient or object from a multitude of angular positions. For this purpose, an x-ray tube is used, with its beam collimated to a fan defining the image plane, in conjunction with a detector array traveling on a circular path around the patient. Typically, $360 \sim$ are covered to collect a complete set of data. Thereafter, the respective image is reconstructed and the patient is shifted a small distance through the gantry for the measurement of the next transverse section. This procedure is repeated slice by slice. To receive images of high quality, it is important that the patient not move during the data acquisition process to avoid unsharpness (similar to that in classical radiography) and motion artifacts (inherent to image reconstruction in CT when inconsistent data are given). Short scan times are desirable to limit such motion effects in single scans. Short total examination times also are desirable to limit motion between scans because movement can cause omission of anatomic levels and discontinuities in multiplanar or three-dimensional (3D) displays. These effects often are a significant drawback to conventional CT. (We refer to "conventional CT" in this article whenever scans are acquired successively, slice-by-slice.) ${ }^{[5]}$

The aforementioned, of course, referred to the traditional X-rays CTs. Nowadays, however, spiral CTs are in use. So, how do these differ? According again to Kalender:

'In contrast, spiral CT is a volume scanning procedure in which the patient is shifted continuously through the gantry. Whereas the radiographic tube and detector system rotates around the patient with data acquired 
continuously, the patient travels typically at a speed of one slice thickness per $360^{\circ}$ rotation. In practice, this means values of 1 to $10 \mathrm{~mm} / \mathrm{sec}$. Relative to the patient, the focus of the $\mathrm{x}$-ray tube describes a spiral or helical path, which led to the different names given to this scanning procedure.' ${ }^{[5]}$

Although it may seem as if spiral CT was rejected by all the professionals during its debut, the matter was more of a division as opposed to an outright rejection ${ }^{[6]}$. In 2016, Wang, Y. Zhang and colleagues authored a paper which discussed an investigation into the diagnostic value of multi-slice spiral CT in renal trauma ${ }^{[7]}$. According to the authors, MSCT is $100 \%$ accurate for kidney injury. These findings are of major value for all parties as they provide us with yet another tool that may aid in the maintaining and advocating of patient's well-being. As per the authors of the paper,

'The outcomes of MSCT enhanced scanning achieve a 100\% diagnostic accuracy rate, which was confirmed by surgical findings. We concluded that the enhanced MSCT scan permits reliable detection of renal trauma and the associated organ or tissue injuries, providing important clinical value for the diagnosis and classification of renal trauma or internal organ injures.' ${ }^{[7]}$

Another relatively modern application of CTs would be using them to speculate on the likelihood of ACS occurrence through the identification of Vulnerable Plaques (VPs)/High-risk plaques (HRPs) (which were defined as: ' $\geq 2$ features, including positive remodeling, low-attenuation plaque [LAP], and spotty calcification' ${ }^{[8]}$ via CTAs. Although this is something that we definitely wish becomes manifest in day-to-day medical practice, we tend to agree with the following quote by Dr. Goldstein:

'CTA powerfully documents the presence and quantifies the burden of coronary atherosclerosis. Accumulating evidence supports the notion that plaque characterization identifies patients at risk. These attributes may bring value to various patient populations. But, will CTA constitute a realistic screening or monitoring strategy to detect VP? I am both hopeful and doubtful. As a moment's "snapshot in time," imaging (CTA or invasive direct coronary imaging) typically documents a multitude of plaques, only some of which exhibit HRP features, and not all such induce ACS; further, many ACS culprits do not exhibit HRP features at a prior moment in time. Further problematic is that given the chronic nature of atherosclerosis, sequential imaging over time would be necessary to detect plaque transitions from stable to VP, and even regular intervals may never sufficiently provide for this purpose; thus, as a monitoring strategy, CTA seems unrealistic (futile). Regardless, in those cases in which CTA does document HRPs, further natural history studies will be necessary to satisfy Koch's postulates to convict such lesions as VPs, let alone justify preemptive stenting of such putative culprit precursors.' ${ }^{[8]}$

In line with the topic, we believe it necessary that we display the argument set forth by Professors Sun, Choo and NG in their 2012 paper ${ }^{[9]}$ with which we also agree:

'in selected patients coronary CT angiography is regarded as a reliable alternative to invasive coronary angiography. With high-quality coronary CT imaging increasingly being performed, patients can benefit from an imaging modality that provides a rapid and accurate diagnosis while avoiding an invasive procedure.

Despite the tremendous contributions of coronary CT angiography to cardiac imaging

A comprehensive evaluation of atherosclerotic plaques requires the detection of both lumen and outer vessel wall borders throughout the coronary tree. Semiautomatic multislice CT approaches have been reported to quantify plaque volume, burden and the degree of remodelling. However, automatic detection of outer artery wall borders remains a major challenge, as it is usually affected by subtle differences in image gradients, 
particularly in the peripheral coronary segments. Thus, the development of advanced quantitative algorithms in combination with advances in CT scanner technology may lead to improved quantification of plaque characteristics and guide percutaneous coronary interventions. Despite these promising results, coronary CT angiography is unable to determine which plaques are "vulnerable" or unstable from those that are stable. Therefore, differentiation of lipid rich content from fibrous content with multislice CT remains challenging owing to considerable overlap in the attenuation values of lipid and fibrous tissue. Atherosclerotic plaque dimension and geometry play an important role in the natural progression of the disease and may have an important clinical predictive value. It is widely accepted that plaque composition rather than the degree of luminal narrowing may be predictive of the patient's risk for cardiac events.' ${ }^{[9]}$

CTs have also manifested themselves in oncology as they work 'hand-in-hand' with SPECTs to identify, localize and characterize endocrine and neuroendocrine tumors ${ }^{[10]}$. It seems as if the SPECT/CT combination significantly aids in increasing the accuracy of the ${ }^{~}{ }^{131}$ I scan in differentiated thyroid cancer by better distinguishing cervical lymph node metastases from residual thyroid tissue, lung from mediastinal metastases or bone from soft tissue metastases' ${ }^{[10]}$. This seems to be rather significant as the authors argue that the diagnostic and follow-up accuracy is increased $21-73.9 \%$ on follow-up as well as diagnostic scans ${ }^{[10]}$. Furthermore, the authors argue 'In particular, SPECT/CT led to modification of therapeutic management in a fraction as high as $35-47 \%$ and avoided unnecessary treatment in about $20 \%$ of the patients; stratification of risk was modified by the SPECT/CT findings in $25 \%$ of the patients' ${ }^{\text {' } 10]}$.

CT scans, as well as ultrasound (US) scans are used in the detection and localization of Gastroenteropancreatic (GEP) tumors. Unfortunately, they do not seem to be satisfactorily capable of 'Precise identification and localization of small tumour foci......... with a reported low and widely variable sensitivity ranging between 13 and $85 \%$. ${ }^{\text {[10]. }}$. According to the authors:

'In cases with a completely negative planar and SPECT somatostatin receptor scintigraphy, it is usually not justified to perform SPECT/CT. On the other hand, in cases with abnormal tracer accumulation SPECT/CT improves the diagnostic accuracy by enabling to distinguish physiological tracer accumulation or activity due to benign lesions from tumour uptake; thus, in the majority of patients it also avoids the need for delayed acquisitions. Octreoscan ${ }^{\circledR}$ SPECT/CT has shown $86 \%$ specificity and $85 \%$ positivepredictive value (PPV); it also changed patient management in 3-14\% of the cases, mainly by sparing unnecessary surgery. In particular, hybrid imaging helps in more accurately defining the organ involved and the overall extent of disease, including possible invasion of adjacent tissues (through analysis of the CT component of the study). SPECT/CT can therefore be crucial for choosing the most appropriate treatment for each individual patientsurgery or chemoembolization if the tumour is confined to a single organ without invasion of surrounding tissues, systemic therapy if the disease is extensive or disseminated.' ${ }^{[10]}$

A number of oncological/endocrinological cases are further discussed in the paper.

In summary, this is how CTs evolved ${ }^{[11]}$ :

1917: Johann Radon presented an algorithm for creating an image from a set of measured data. ${ }^{[11]}$ 1950-1970: Cormack makes theoretical advances on Radon's work ${ }^{[11]}$

1972: Hounsfield builds the world's first CT scanner ${ }^{[4,5,11]}$

1979: Hounsfield and Cormack's work is recognized and they receive the Nobel Prize in Medicine ${ }^{[11]}$ 1998: World's first 4-slice CT introduced ${ }^{[6,11]}$

2004: 'the advent of scanners for the simultaneous acquisition of 64 slices per rotation.' [11] 2005: Dual-source CT introduced ${ }^{[11]}$ 
In these modern times, it is unfathomable for a healthcare provider to not only be familiar with what an ultrasound scan is, but for it to be an integral part of the hospital, clinic, etc. But, it wasn't always like this and, relatively speaking, the ultrasound only appeared recently into healthcare settings. These advancements are usually made when a medical doctor and physicist/engineer join forces to improve patient care ${ }^{[12]}$. We believe that such collaborations are a necessity if we ever wish to truly evolve to the point where we may, as a unity, face the myriad challenges the bestow us both as a species and as individuals. As Dr. Duck so gracefully articulated this point: 'In due course, typically as a result of a medical doctor working in partnership with an engineer or scientist, clinical applications are explored.' ${ }^{[2]}$. The first investigations into ultrasounds could be traced back to the 1890 s, which was only $\sim 130$ years ago ${ }^{[12]}$. The reason we use the word 'only' is in reference to how anachronistic medicine is. In fact, according to Pickover ${ }^{[13]}$ :

'Shamanic practices, involving healers who appear to be in contact with a spirit world, probably originated in Paleolithic (Old Stone Age) times. For example, evidence for Mesolithic (Middle Stone Age) shamanism was found in Israel in the form of an old woman from a burial dating to around 10,000 B.C. The importance of this woman, along with her possible close association with nature and animals, is suggested by the special arrangement of stones by her body, along with 50 complete tortoise shells, a human foot, and remains of birds, boars, leopards, cows, and eagles. Today, the vast majority of the traditional Nguni societies of southern Africa make use of sangomas who employ herbal medicine, divination, and counseling.' ${ }^{[13]}$

Back to ultrasounds:

Following the 1890s introduction, it would be nearly 50 years before the clinical application of ultrasounds became a part of the medical doctors' paradigm ${ }^{[12]}$. Shortly thereafter, ultrasounds would play a role in both diagnosis and imaging in medical practice ${ }^{[12]}$. One of the first applications of this was in the medical field of ENT, particularly in evolving our understanding of how our hearing functions ${ }^{[12]}$. In quoting of Duck:

'Rudolph Koenig's publication in 1899 marks the first serious exploration of ultrasonic waves in air. Koenig demonstrated that ultrasonic waves up to $90 \mathrm{kHz}$ could be generated using a series of small tuning forks and steel bars only a few millimeters long. However, they were not loud enough for audiological testing and Max

Edelmann then used an improved Galton whistle to generate louder ultrasonic frequencies up to $110 \mathrm{kHz}$. Eventually, using a series of careful measurements, Franz Schultze confirmed Preyer's estimate of $20 \mathrm{kHz}$ as a reasonable upper threshold for human hearing, so setting the lower limit of the ultrasonic spectrum that remains generally accepted today.' ${ }^{[12]}$

It was in the same year, 1899, that P Lebedev first evidenced Maxwell's prognostication of the existence of radiation pressure in an electromagnetic wave ${ }^{[12]}$. In 1902, Lord Rayleigh analyzed the relationship between energy density and radiation pressure in acoustic and electromagnetic waves. One year later, in 1903, Belarusborn W Altberg (1877-1942), who worked under the aforementioned Lebedev, became the first to 'use radiation pressure to measure the intensity of a sound wave' ${ }^{[12]}$. According to Duck, 'This work marks the first occasion in this story when a key experiment is directly relevant to later developments in the physics of medical ultrasound. Radiation force is now the primary means to measure acoustic power in beams used for therapeutic and diagnostic applications of ultrasound, and details are given elsewhere in this history. It also forms the basis of radiation force elastography.' ${ }^{[12]}$.

Altberg, however, was not yet donne establishing himself in history. In 1907, Altberg would again make history by displaying that Duddell's singing arc, which was articulated in a 1901 paper ${ }^{[14]}$, possessed the ability to emit acoustic waves at ultrasonic frequencies ${ }^{12,15}$. According to Duck,

'In his delightful acoustic experiment, he investigated the spectrum of the pulsed acoustic waves generated by 
a spark discharge, using a diffraction grating made from glass rods. He measured the diffraction patterns using the radiation force exerted on a 4x12 mm mica vane suspended in a draft-proof box by a quartz thread, observing its displacement by the radiation force. From the angle of the main diffraction lobe he concluded that he was able to generate wavelengths as small as $1 \mathrm{~mm}$, in other words, frequencies in air of a little over $300 \mathrm{kHz} . '$

4 years later, in 1911, the aforementioned Lebedev and a student of his, Neklepajev were able to justify why Altberg had been unable to detect wavelengths shorter than $1 \mathrm{~mm}$. As per Duck, 'It resulted from their absorption, for which the coefficient is dependent on the square of the frequency, so placing a limit on the useful penetration of higher ultrasonic frequencies through air.' ${ }^{[12]}$

Starting in 1912, a paradigm shift regarding the utility of ultrasounds manifested. This paradigm shift can be attributed to LF Richardson (1881-1953) who authored the world's first documentation in which the notion of ultrasounds being used underwater was written ${ }^{[12]}$. The infamous tragedy surrounding the sinking of the titanic may have catalyzed Richardson's efforts as he, as per Duck, 'immediately submitted two patent applications in quick succession to the British Patent Office $[18,19]$, the second proposing an underwater ultrasonic system instead of the airborne system of the first. The purpose of the apparatus was to warn a ship of its nearness to an object ahead.'

In 1915, Constantin Chilowsky, who was convalescing from Tuberculosis in Switzerland, developed a plan that would make use of an ultrasound system in the detection of submarine ${ }^{[12]}$. In this proposal, Chilowsky would argue for the abandon Richardson's underwater whistle and instead for the use of a magneticallydriven diaphragm as a source of ultrasound ${ }^{[12]}$. This proposal would eventually end in the hands of the renowned French physicist Paul Langevin (1872-1946) who would, along with his team work tirelessly to manifest the proposal set forth by Chilowsky ${ }^{[12]}$. According to the aforementioned Duck,

“On 17 Feb 1917, when Maurice de Broglie visited London to present Langevin's report to the British Board of Inventions and Research (BIR) he declared that the methods described 'represent the result of two years' continuous work, during which other methods have been tried over and over again without success. Though it is probable that they may be eventually improved, it appears certain that time will be saved by not departing (for the present) from the constructional details hereafter described." [12]

In February of 1918, a signaling distance of $8 \mathrm{~km}$ was achieved 'Operating in pulse-echo mode, clear echoes were obtained for the first time from a submarine' ${ }^{[12]}$. In March of 1918, Boyle would detect submarine echoes from 500 yards, using the same transducer for both transmission and reception.

The reason for the focus on naval efforts was because of the 1914 sinking of 3 British cruisers by torpedoes launched form submarines ${ }^{[12]}$. However, the detection of submarines via ultrasounds would not see action as peace was announced prior to it being used in war.

Between the years of 1922 and 1932, Boyle published 25 papers shining forth the basic physics of ultrasound ${ }^{[12]}$. It is believed that Boyle's 1922 paper on acoustic cavitation was the first to address this topic ${ }^{[12]}$. Between this and the $2^{\text {nd }}$ World War, advancements primarily took place in 3 areas of ultrasonic:

1) Acoustics,

2) Applications of high-density ultrasound in biology, engineering, and chemistry, and

3 ) 'the development of underwater sensing for commercial and naval purposes' [12]

By the start of the $2^{\text {nd }}$ world war, ultrasounds made a comeback in anti-submarine detection technology. 
Ultrasounds and medicine

According to Duck:

'Unsurprisingly, a few laboratories around the world started to investigate whether ultrasound had the potential to treat cancer. Studies were reported from Europe, Japan and the USA, but the results were equivocal, whether used alone or in conjunction with radiotherapy.

It was left to the German physicist Reimar Pohlman (1907-1978) to establish the use of ultrasound for therapy. Pohlman was a physics and chemistry graduate from Heidelberg and Berlin, and gained his $\mathrm{PhD}$ in

1932. In 1935, now assistant at the Physikalisch-Chemischen Institut of the University of Berlin, he had commenced research on air-borne ultrasound. A year later he published his first patent for a 'Device for the detection of defects in solid and liquid bodies by means of sound, in particular ultrasound waves'. In 1939 he proposed a means for imaging the ultrasound wave that became known as the Pohlman cell.' [12]

In 1939, Pohlman, Richter and Parow published their paper titled 'Uber die Ausbreitung und Absorption des Ultraschalls im menschlichen Gewebe und seine therapeutische Wirkung an Ischias und Plexusneuralgie' ${ }^{[12,16]}$. The paper was addressing the utility of ultrasound therapy and reported some rather positive results in so far as some neurological disorders were concerned ${ }^{[12,16]}$.

Some advancements were taking place, but, according to Dognon's 1953 publication:

'Obviously, it is urgent to apply methods already rich in results in the industrial field to the study of the human body. Unfortunately, the situation is much less favourable, because the body, the organs, and even most of the tissues are roughly heterogeneous in terms of their acoustic properties. The air, often present, constitutes, in the form of bubbles or thin sheets, interfaces of total reflection. Other more or less marked reflections occur at each zone of contact between tissues of different density or compressibility' ${ }^{[12,17]}$

Nowadays, clinicians associate ultrasound with abdominal imaging (in, for example, cholycystitis) and in the field of Obstetrics and Gynecology. The later association, and the paradigm shift associated with said association, could be traced back to Ian Donald and colleagues' 1958 paper ${ }^{[18]}$. In quotation of Professor Campbell:

'It is often difficult to know when most developments in medicine actually begin. They tend to evolve and many people will claim the credit of being the first to make the breakthrough. With Ultrasound in Obstetrics and Gynaecology there is no such doubt for it had a very definite beginning with the1958 classic Lancet paper (Donald et al., 1958) by Ian Donald, John McVicar, and Tom Brown "The investigation of abdominal masses by pulsed ultrasound".' [18]

Following this, Campbell clarified that 'Actually this is an unfortunate title because it does not identify what was truly unique about the paper' ${ }^{[18]}$. We wholeheartedly agree with Campbell as it is true that the title is rather misleading given the fact that this the first time ultrasound images of a fetus manifested themselves ${ }^{[18]}$. From there on out, advancements and clinical wisdom have made ultrasounds an integral part of Obstetrics and Gynecology. But, what was the situation like before 1958 ?

For starters, in 1949, Ludwig used the technology's predecessor to detect gallstones ${ }^{[18]}$ and Wild used it to detect breast masses. This is, of course, in addition to the aforementioned history of ultrasound development.

By the late 1950s, Donald and Brown developed 'the world's first contact compound 2D ultrasound scanning machine called the Diasonograph. He and his team published their seminal pioneering paper in the Lancet in 
1958. It begins with the physics of ultrasound scanning techniques, safety experiments, ultrasound images of pregnancy, the fetus and gynaecological tumours, and a really detailed description of the strengths, weaknesses and potential of this new technique. The ultrasound images were crude and bistable (i.e. totally lacking grey scale)' ${ }^{[18]}$. Keep in mind that this was over 6 decades ago, and the Diasonography looked nothing like our modern-day ultrasound machines.

In 1962, Kossoff built what was known as the 'Octason static scanner', however, it wasn't until the late 1960s that the Octason static scanner truly manifested itself as a promising endeavor ${ }^{[18]}$. This was because of the image quality, in the later part of the decade, it would Kossoff who would introduce the scan converter; this would be the introduction of the concept of grey-scale scanning ${ }^{[18]}$. Beautifully articulated by Campbell is the following:

'The Octason mark 2 images in the late 1960's were spectacularly good in demonstrating fetal anatomy but the Octason's time of brilliance was short-lived following the introduction of the scan converter into contact static scanning machines and the convenience of the latter equipment won the day.' ${ }^{[18]}$

What we find rather fascinating is the metaphorical and, as far as we can tell, completely coincidental, association between this occurrence and the aforementioned quote by Professor Röentgen

'The scientist must consider the possibility, which usually amounts to a certainty, that his work will be superseded by others within a relatively short time, that his methods will be improved upon and that the new results will be more accurate and the memory of his life and work will gradually disappear.' ${ }^{[1]}$

In 1963, Donald and his team, in keeping with the trailblazer, paradigm-shifting, innovative mentality they seem to have been possessed by, had illustrated the diagnosis of the hydatid mole (inclusive of its characteristic snowstorm appearance), had illustrated the concept of the assessment and growth of the early gestational sac via the so-called 'full-bladder technique' and the illustration of the diagnosis of complications of early pregnancy ${ }^{[18]}$.

One of the primary concepts of any Obstetrics and Gynecology course is the topic of placenta praevia. This is directly caused by the unfathomable severity of the condition and the emergency situation it creates. As Campbell articulated 'Accurate location of the placenta was the holy grail of antenatal diagnosis in the early 1960 's for placenta praevia was the cause of significant maternal mortality due to severe haemorrhage in late gestation.' ${ }^{[18]}$. Up and until this point, the methods in use were incapable of illustrating the placenta's lower edge ${ }^{[18]}$. In 1966, Gottesfeld and colleagues' paper (titled 'ULTRASONIC PLACENTOGRAPHY-A NEW METHOD FOR PLACENTAL LOCALIZATION) ${ }^{[19]}$ discussing ultrasound sonography was published ${ }^{[18,19]}$. It is the first paper discussing the topic ${ }^{[18]}$. The research project was exquisitely done, according to the authors 'This project was initiated to assess the ability of ultrasound to visualize the placenta and to determine its intrauterine position. The results of such a study in over 200 cases of pregnancy form the basis of this report.' ${ }^{[19]}$. Although the reported results were highly impressive (anterior, lateral and fundal wall boundaries could be visualized), there still existed the fact that, as per the authors, 'In many instances of posterior placental localization, the typical ultrasonic placental pattern could not be seen and its localization had to be reached by exclusion.' ${ }^{[19]}$. Given how beautifully the upcoming notion was articulated, we decided to quote is as is:

'The results presented show that ultrasonic visualization has considerable potential as a practical technique for determining placental location. In the present series the accuracy was approximately 97 per cent and the errors were not confined to any particular placental location' ${ }^{[19]}$

Following this, the authors prophesized the following:

'As equipment improves, it should be possible to obtain better resolution of the placental echo pattern, thus providing a potential technique for diagnosing circumvallate placenta, marginal sinus separation, and to study 
the placenta in relation to certain fetal developmental abnormalities.' ${ }^{[19]}$

Only 2 years later, in 1968, a major stride would take place with the publication of Donald and Abdulla's paper which was able to localize the entirety of the placenta, including the posterior border ${ }^{[18]}$. The paper, titled 'PLACENTOGRAPHY BY SONAR' ${ }^{[20]}$ starts by clearly differentiating localization of the placenta and placentography, they used a Diasonograph and a pulsed frequency of $1.5 \mathrm{MHz}$ following the $32^{\text {nd }}$ week of gestation ${ }^{[20]}$. The study was larger, with a total of 675 cases; and it concluded an error incidence of $6 \%$ [20]. According to the authors:

'Placentography by sonar compares favourably with existing techniques.........In these subsequently confirmed cases the accuracyrate was over 94 per cent. The technique is simple in the hands of an average clinician, and the patient is involved in neither discomfort nor hazard from ionizing radiation. The results are immediate and no safety precautions are necessary.' [20]

In 1970, Sunden published 'PLACENTOGRAPHY BY ULTRASOUND' in which they illustrated rather agreeable results favoring ultrasounds, according to Sunden 'The reliability of this ultrasound method was 95.6\%, a figure comparable with those produced by other techniques.' ${ }^{[21]}$. In regards to placenta praevia, the results of this study were rather favorable, according to the authors:

1) No false positive results took place, and

2) Of a total of 8 cases of placenta praevia, 7 were diagnosed correctly (in other words, there was a single false negative result)

The author articulated the following in regards to the results:

'In 1 case-examined [in reference to the aforementioned false negative finding] in the 29th week of pregnancy- the low lying placenta, dorsally on the ultrasound picture, was judged not to reach below the foetal head, but at Caesarean section, it was found to cover 113 of the internal os. This was the only false negative result.' ${ }^{[21]}$

In regards to fetal biometry, ultrasounds also played a role in seeing it evolve to become what it is today. According to Campbell:

'The initial studies in fetal biometry began with using a blind A- scan measurement of the biparietal diameter (BPD) and James Willocks from Donald's department published an interesting paper on head growth in the third trimester showing different rates of growth between growth restricted and normally growing fetuses. The method was intrinsically inaccurate however and precision was needed for meaningful biometry.' ${ }^{[18]}$

Ultrasounds also played, and still do play, a major role in the detection of fetal abnormalities. In 1964 and 1970, Bertil Sunden and William Garrett respectively made subjective reports addressing the prenatal diagnosis ${ }^{[18]}$. Sunden diagnosed anencephaly whilst Garrett diagnosed polycystic kidneys ${ }^{[18]}$. However, the true beginning of prenatal diagnosis via ultrasound began with Campbell and colleague's 1972 paper which was published in the Lancet which reported a diagnosis of anencephaly at 17 weeks pregnancy which, ergo, resulted in the elective termination of said pregnancy ${ }^{[18,22]}$. In 1975, Campbell was able to report the diagnosis of spina bifida ${ }^{[18]}$.

In 1977, Campbell again reported some rather interesting findings, according to Campbell of the United Kingdom's 2013 paper in FVV:

'By 1977 he [referring to Campbell] was able to report on 329 high risk pregnancies examined between 16 
and 20 weeks in which ultrasound detected 25 of the 28 neural tube defects; 10 of the 13 cases of spina bifida were detected with the false negatives being low sacral lesions' ${ }^{[18,23]}$

One year later, in 1978, Hobbins and colleagues' of Yale reported further findings using ultrasounds to diagnose a number of abnormalities ${ }^{[18,24]}$. According to Hobbins and colleagues:

'With ultrasound it was possible to examine internal fetal anatomy and to identify abnormalities of the fetal cranium, spine, chest, abdomen, and limbs.

Based on ultrasonically derived information, second-trimester patients can be offered information concerning the status of their fetuses at risk genetically and physicians can better manage third-trimester patients with diagnosed fetal deformities.' ${ }^{[24]}$

Magnetic Resonance Imaging (MRI), magnetic resonance angiography (MRA), functional imaging (fMRI) magnetic resonance spectroscopy (MRS) and Mammograms

This is probably the only entry of these to have stirred up controversy, especially to the extent it has (involving, as we shall see, accusations directed towards the Nobel Prize committee and a rather peculiar association with the infamous Cold War). Let's, however, start by discussing the $40+$ year journey leading to today. For simplicity and illustration purposed, we will also be discussing mammogram and their history in this division of the project.

Before discussing MRIs and their underlying technologies, it is imperative that we introduce the individuals who played direct roles in allowing these unfathomable feats of technology to become manifest. We will first be starting with the individual that has been, according to many, maltreated and underappreciated by the scientific community - that is Dr. Raymond V. Damadian.

Born in NYC in $1936^{[25]}$, little did little Raymond's parents know what accomplishments awaited the young boy. By 1960, Damadian, now approximately 24 years of age, had received a scholarship (Ford Foundation Scholarship) to attend the University of Wisconsin (majoring in mathematics and chemistry) and had graduated from the Albert Einstein School of Medicine ${ }^{[25]}$. Next, Damadian would complete his residency at SUNY Downstate Medical Center ${ }^{[25]}$. Following this, Damadian worked as a postdoctoral fellow in nephrology with Dr. NS Bricker at the nephrology division of the Internal Medicine Department at the Washington University School of Medicine ${ }^{[25]}$.

Between the years of 1963 and 1965, Damadian would join Harvard University where he would undergo postdoctoral training under Arthur Solomon; this is when Damadian would be introduced to NMR ${ }^{[25]}$. Between 1965 and 1967, Damadian would serve in the United States Air Force assigned to the School of Aerospace Medicine at Brooks Air Force Base ${ }^{[25]}$.

In 1967, Damadian re-joined SUNY Downstate as an Assistant Professor in the Department of Medicine. Here, he would institute a biophysics research laboratory where he would, at first, focus his efforts on to, according to the authors of a paper on the topic, 'ion exchange mechanisms and the controversy regarding the existence or lack thereof of a so-called sodium pump.' ${ }^{\text {[25] }}$. However, it was not this that has resulted in Damadian becoming the name he is now. That would be the focus shift, in so far as interest is concerned, to NMR which he was first introduced to, as aforementioned, during his time at Harvard ${ }^{[25]}$. Mattson and Simon ${ }^{[26,27]}$, when discussing the work of Damadian had the following 
to comment:

'The missing link needed to go from the test-tube NMR of chemical solutions to the MRI of human tissues was supplied by Dr. Damadian. His 1971 paper in Science contained two key discoveries that were the missing link.

The following landmark steps in the development of NMR scanning were provided by Dr. Damadian: 1) the scientific research and the theory of the cell developed by Damadian that led him to consider NMR as a method for detecting cancer; 2) his discovery of the cancer NMR scanning signal in animal tissue together with the demonstration of the diversity of NMR relaxations among healthy tissues; 3 ) his filing of the original and foremost patent on NMR scanning; 4) his achievement of the first whole-body NMR scan of a human and the resultant image; and 5) his development of the world's first commercial NMR scanners' [25,26,27]

Damadian receiving the recognition he deserved and the controversy regarding the Nobel Prize:

In 1974, Damadian was granted a patent for his revolutionary imaging method, (U.S. Patent 3,789,832) ${ }^{[25] .}$ According to the authors of the 2007 article illustrating Damadian's achievements as well as highliting the controversial 2003 situation regarding the Nobel Prize (which we will be alluding to further down in this article) [25], 'As a matter of fact, his patent required the creation of a new subclass numbered 653.2 within Class 128. Another patent would not join that class for another 7 years' ${ }^{[25]}$. In 1988, then US President Reagan presented both Dr. Damadian and Dr. Lauterbur with the National Medal of Technology ${ }^{[25]}$. One year later, in 1989, Damadian would be inducted into the National Inventors Hall of Fame ${ }^{[25]}$. In the 1990s, Damadian had to actively protect his patents through a number of lawsuits, a rather well-known lawsuit was the one involving General Electric ${ }^{[25]}$, according to the authors of the aforementioned paper, "Ultimately the Supreme Court upheld the complaints by FONAR Corp. and Doctor Damadian, thus confirming an earlier jury's verdict finding infringement on Damadian's patent and awarding \$128 million in damages.' [25]. In 2001, MIT's Lemelson program awarded him with its Lifetime Achievement Award ${ }^{[25,28]}$, according to the program's website:

'Raymond Damadian was awarded the Lemelson-MIT Program's Lifetime Achievement Award in 2001 for his pioneering work in magnetic resonance scanning technology.

Damadian has received over 45 patents (some co-invented) for improvements to his MRI scanner. Among his innovations are a full-sized MRI operating room that allows unrestricted patient access and can fit a surgical team and equipment, and the Stand-Up MRITM — the only scanner capable of scanning patients while standing.

Though FONAR has faced opposition from competitors throughout the years, Damadian has persistently

fought patent infringement and, as a result, continues to be an ardent advocate of the independent inventor.

A few years later, in 2004, Damadian was awarded the Franklin Institute's Bower Award for Business Leadership in the Field of Brain Research ${ }^{[25]}$. In 2008, according to the Lemelson program's website 'Damadian received the Caring Award by the Leslie Munzer Neurological Institute of Long Island (LMNI) for his invention of the MRI and his work at FONAR (2008).' ${ }^{[28]}$. Damadian is the founder of FONAR; as a matter of fact, he left his full-time position at SUNY Downstate in 1979 to head and found FONAR ${ }^{[25]}$. 
The history of MRI starts in approximately 1976 with a scan of a human finger by a group at Nottingham which was followed, one year later by an image of the human chest (the first of its kind) by Damadian ${ }^{[29,30,}$ ${ }^{31]}$. According to Heggie:

'The appearance of that unit [in reference to what is known as the 'Indomitable'] may be contrasted somewhat with that of the modern superconducting MRI units operating at field strengths, typically between 1.5 and 3T.

These new units are capable of producing images with essentially isotropic spatial resolution at the sub millimetre level and even whole body images made by stitching together images acquired in a step and scan manner'. ${ }^{[29]}$

As aforementioned, Damadian and the MRI evolvement process was involved in a controversial situation with the Nobel Prize committee when, in 2003, they awarded Lauterbur and Mansfield the Nobel Prize in Physiology or Medicine for their work regarding the development of MRI technology; Dr. Damadian was omitted and this, as expected, created a controversy ${ }^{[25]}$. According to the available information, the Noble Prize could be awarded to up to 3 scientists ${ }^{[25]}$. In this case, it seems as if Dr. Damadian was purposefully omitted - why that is remains to be known. It seems as if this may be due to the disagreements that Damadian and Lauterbur had; according to Rackman of Bar-Ilan University, there exists a 'controversy between two great contributors to MRI, Dr. Raymond Damadian and Dr. Paul Lauterbur' ${ }^{[25,32]}$. This, however, is not the first instance in which this notion has been alluded to. In 1973, Lauterbur published a paper in Nature in which he reported the findings of his use of the technology for image production purposes ${ }^{[33]}$, the issue seems to have first arisen when Lauterbur did not mention Damadian's work in his article ${ }^{[25,33]}$. For our purposes, we will not be insinuating whether or not that course of action was purposeful. The authors of the 2007 paper commented the following in regards to the controversy that is existent to this very day:

'Doctor Lauterbur produced the first image of a live subject, a clam, and published the results in Nature in March 1973. He neglected to mention Damadian's work but he did include references which cited Damadian.

This would start a controversy that continues to the present day.

The Nobel Prize in Physiology or Medicine can be awarded to a maximum of 3 scientists for any single discovery but in this instance was only given to 2. Excluding Doctor Damadian seems to be a serious and purposeful omission. The deliberations of the Nobel Committee remain closed for 50 years and only after this time passes will the world know what contributed to the decision to exclude Damadian.' [25]

Just over a decade following the omission of Damadian, Kauffman wrote an article ${ }^{[34]}$ illustrating that issues exist within the committee and have existed for a considerable length of time. In the words of Kauffman:

'Although the denial of the Nobel Prize in 1905 and 1906 to Mendeleev for the periodic table, the Rosetta Stone of chemistry, is probably the best known example of outrageous disgrace in the awarding of the prizes, another case of bias that occurred almost a century later - a decade ago-deserves our attention [in reference to the situation with Damadian].' [34]

Kauffman was not the only individual to comment on the actions of the Nobel Prize committee. Ulf Lagerkvist once commented the following: 
'It is in the nature of the Nobel Prize that there will always be a number of candidates who obviously deserve to be rewarded but never get the accolade. Of course it is an impossible task that the Academy has struggled with for more than a century. Maybe one can claim that it has done a fairly good job after all. Nevertheles there have been unfortunate sins of omission and the most outrageous is that committed against Dmitri Mendeleev. It is indeed a pity that his name does not appear in the distinguished list of laureates. It would certainly have added to both the prestige of the Nobel Prize and the Royal Swedish Academy of Sciences' $[34,35]$

Damadian was not one to accept such injustice. He claimed that he had been the one to invent the MRI and that Lauterbur and Mansfield had only refined the technology ${ }^{[34,36,37]}$.

According to Kauffman:

'Because Damadian was not included in the award even though the Nobel statutes permit the award to be made to as many as three living individuals, his omission was clearly deliberate. The possible purported reasons for his rejection have included the fact that he was a physician not an academic scientist, his intensive lobbying for the prize although other candidates have done so, his supposedly abrasive personality, and his active support of creationism. None of these constitute valid grounds for the denial.' [34]

NMR. The technology underlying MRIs first came into being through the work of Isidor Isaac Rabi 18981988) ${ }^{[34,38] .}$.

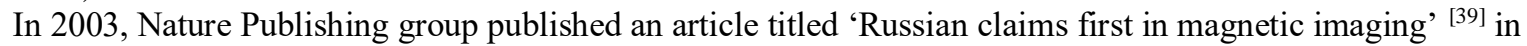
which it is argued that the technology was first developed by Vladislav Ivanov who was, at the time, a lieutenant in the Red Army. According to the article:

'In Ivanov's case, the momentum was quashed by the state committee in St Petersburg, whose records show that Ivanov submitted an application, "Method of examination of the internal structure of material bodies", in 1960. The application defined Ivanov's principles in detail, and included a diagram of a device identified as

MRI equipment. The document was assigned the number 659411/26, and was forwarded for review to scientific institutes in St Petersburg, then known as Leningrad.

His options for appeal were limited: Red Army officers could not publish abroad.

Years later, when the work of Lauterbur and Mansfield came to the world's attention, the committee revisited Ivanov's application and gave its assent. But by then, Ivanov says, Soviet science had fallen too far behind.' [39]

The aforementioned Kauffman alludes to this notion in his paper. This is what he said:

'In 1960 24-year-old Vladislav Aleksandrovich Ivanov (then a Soviet army lieutenant, now Professor, Doctor of Chemical Sciences, and Head of the Department of Measurement Technologies and Computer Tomography at the Saint Petersburg Institute of Precision Mechanics and Optics) was serving at a rocket 
airfield in the town of Suchan (Maritime Territory) and was engaged in natural objects navigation based on the magnetic field of the earth. He filed four patent applications with the U.S.S.R. State Committee for Inventions and Discovery at Leningrad, all of which were rejected at the time because they were considered unfeasible. One of these, "A means of investigating the internal structures," Application No. 659411/26, was registered on March 21, 1960, for a Magnetic Resonance Imaging device.

However, the original idea of applying NMR to medical imaging (MRI) was first proposed by Raymond V, Damadian, M.D., who was granted a U.S. patent for an MRI scanner, and founded a company to manufacture such scanners.' ${ }^{[34]}$

Although MRI machines are expected in most major hospitals around the world, there still exists the possibility of issues being associated with it - or, at least, an existence of contraindications to its use. According to Dill ${ }^{[40]}$, this list of possible contraindications to the use of MRIs includes, but is, in possibility, not limited to, the following:

1) Vascular Clips

2) Foreign bodies

3) Coronary and peripheral artery stents

4) Aortic stent grafts

5) Prosthetic heart valves and annuloplasty rings

6) Cardiac occluder devices

7) Vena cava filters and embolisation coils

8) Haemodynamic monitoring and temporary pacing Devices

9) Haemodynamic support devices

10) Permanent cardiac pacemakers and implantable cardioverter-defibrillators

11) Retained transvenous pacemaker and defibrillator leads

12) Permanent contraceptive devices

13) Cochlear implants

14) Tattoos and cosmetics

15) Claustrophobia

16) Pregnancy and postpartum

17) MRI AND CONTRAST AGENT

18) Renal insufficiency ${ }^{[40]}$

Mammograms: An Overview

As clarified by Feig in their 1993 paper ${ }^{[41]}$, mammograms differ from other radiological technologies in that they present with a number of technical challenges the pioneers of this technology had to overcome. In the words of Feig:

'The technical requirements for mammography differ considerably from those of other diagnostic studies........ High resolution is needed to visualize microcalcifications and trabeculae often as small as 0.1 $\mathrm{mm}$. Short exposure times are necessary to prevent motion unsharpness. Observable differences in radiographic contrast must be obtained from tissues that possess a relatively narrow range of inherent densities. Also, both the thinnest anterior tissues and the thicker posterior portions of the breast must be portrayed on the same image without overexposure or underexposure respectively. The posterior breast and axillary tail must be projected away from the overlapping rib cage structures. Radiation dose must be kept 
within acceptable limits because mammography will often be performed as a screening procedure where the yield of unsuspected cancer is extremely low compared with the much larger number of women examined.'

The notion that underlies the manifesting of the modern-day mammogram can be traced back to $1910^{\text {[41] }}$ through the work of Salomon who made the first radiographs of the breast. Salomon's work was of extreme importance. So much so, that, in fact, it was around 40 years ahead of its time; in 1951, calcifications were identified as a 'sole mammographic sign of intraductal carcinoma' by Leborgne ${ }^{[41]}$. These same malignant calcifications were identified by Salomon, but were not elaborated on in the manner Leborgne did ${ }^{[41]}$. Progress in mammograms occurred in the 1920s and 1930s, according to Feig:

'Further progress in mammography did not occur until the 1920s when mammographic techniques for evaluation of palpable breast masses in actual patients were first reported byOtto Kleinschmidt and Erwin Payr in 192711 and Walter Vogel in 1932 from the University of Leipzig.' [41]

By this time, the United States of America had had its first mammogram, which was performed by Warren at Rochester Memorial Hospital in New York back in $1930^{[41,42]}$. Warren had the insight to not only describe what a normal breast should look like on mammography, but to point out the need to scan both breasts and compare them ${ }^{[41,42]}$. Starting in 1938, Gershon-Cohen and Ingleby joined forces and described a number of mammographic findings and their association with benign tumors as well as malignancies within the breast [41,43,44]. The publications took place in 1938 and 1960, respectively. Gershon-Cohen also developed, according to Feig, 'a technique in which two films separated by $0.5 \mathrm{~mm}$ of aluminum were exposed simultaneously. The upper film imaged the thicker juxtathoracic tissues, and the lower film imaged the thinner anterior tissues.' ${ }^{[41]}$.

Another advancement took place in 1949 in the hands of Leborgne who, in the words of Feig 'described two fundamental advances in mammographic technique: (1) use of low-kVp technique (20 to $30 \mathrm{kVp}$ ) to increase image contrast and use of a long cone with a flattened surface at its distal end to produce light compression "to immobilize the breast and to diminish the thickness of it or the pathological area. This is especially useful in fibrous breasts"' ${ }^{[41]}$.

In 1960, Egan contributed another major breakthrough in the field ${ }^{[41]}$ by selecting a 'low-kVp (for high contrast)-high-mA (for adequate penetration) technique using industrial nonscreen (high-detail but higherdose) film.' ${ }^{[41]}$. To evaluate whether or not this was consistent, Egan conducted 1,000 studies. This is how Egan described his technique:

'One roentgenogram [the term mammogram was yet to be coined] of the axilla is obtained and two of the breast, in 2 planes at right angles. These have resulted in good delineation of the quadrants, ease in positioning, and patient comfort with consequent cooperation. The entire breast is positioned on a pliable cardboard holder which may be placed to follow the contour of the chest wall in the oblique position, thus covering the smallest gland. "Kodak Industrial M" film is used.' [45]

In addition, Egan mentioned a few difficulties with the viewing capabilities of the 'Roentgenographic technics'. For example, he reported lower quality imaging in 'late pregnancy or lactation, or in the larger and

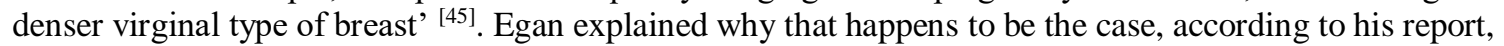
this was due to 'the higher voltage required for penetration' ${ }^{[45]}$. This was primarily an issue when it came to the diagnosing of carcinomas in these aforementioned breasts. So much so, that they were only to be diagnosed if there were secondary signs of malignancy or if the tumor was 'large' ${ }^{[45]}$. This, of course, raises concerns. But, this is, by the standards followed by researchers, a rather anachronistic report. According to 
Egan 'Although not encountered in this study, a small carcinoma may be overlooked under such circumstances.' ${ }^{[45]}$.

Furthermore, another crucial points were illustrated by Egan:

'The roentgenogram must be obtained with the nipple in profile, otherwise nipple retraction cannot be evaluated.

The false positives, benign processes called malignant, were the greatest source of error in this series. These lesions included abscesses, infected cysts, or fibrocystic disease associated with marked sclerosing adenosis and/or ductal hyperplasia.

Postoperative changes following a biopsy for benign disease vaguely resembled localized carcinoma, without calcification or definite secondary signs of malignancy. In the absence of infectious complications, the mammogram reverted to a normal appearance in seven to ten days. Although many patients dated the onset of a breast nodule from trauma, no calcifying hematoma was encountered.

Soft-tissue roentgenography of the breast can be definitive in the diagnosis of malignant, benign, and normal conditions. Provision must be made for indeterminate studies and is just as necessary and valid for the radiologist as for the pathologist. Clinical judgment is mandatory but the typical carcinoma on a roentgenogram should not be ignored' ${ }^{445]}$

In the 1960s, Wolfe, a Detroit-based radiologist clinically developed Xeromammographs ${ }^{[41]}$. This is how Feig described the mammographic evolution set forth by Wolfe:

'Xeromammography was developed clinically during the late 1960s by John Wolfe, a radiologist

from Detroit. In this process, a photoconductive selenium plate is selectively discharged by X rays to form a latent image of the breast, which is then transformed in a visible hard-copy image on paper by means of electrically charged toner particles. Because of its wider imaging latitude, xeromammography could portray the entire breast and rib cage on a single lateral view without overexposure of the anterior tissues or underexposure of the thicker posterior tissues, which occurs when this is attempted with film-screen mammography." [41]

By now, an issue had manifest itself: 'how do we image the entire breast using film-screen mammography?'. By 1976, this question had been answered by Lundgren, a Swedish radiologist ${ }^{[41]}$. Lundgren was a very smart individual, he solved the problem by, in his words, 'Since starting mammography in 1969 I have also used an oblique view [in addition to the lateral and cranio-caudal views], which almost without exception seemed to give an image of the breast covering more area, depicting more of the glandular tissues and being easier to read than the other two, ${ }^{[46]}$. This is how he went on to explain his finding:

'This is based on anatomical factors: with the arm raised the breast can be seen as a continuation of the pectoral muscle in a caudal-medial direction. It is easy to position the patient provided the examination table and the film are placed with one end under the upper part of the pectoral muscle. It is also natural that this 
view gives more information, since in the oblique view the X-ray beam has a shorter course through denser tissues compared with the other two views. This gives better contrast and lessens the probability of lesions being hidden in tissue of more or less equal density. Finally, this view includes the tail of the glandular tissues of the breast, which can seldom be visualized in a cranio-caudal view, and not often in a lateral .' [46]

The findings illustrated in Lundgren were so significant that, up and until this very day, shy of 50 years following this realization, oblique views of the breast on mammogram are used.

Up and until that time, a significant percentage of mammograms were performed xeromammographs. This technique is not as commonly used nowadays ${ }^{[41]}$.

In 1974, a new configuration of mammography x-ray tube. According to Feig 'The cathode was oriented toward the base of the breast to maximize radiation intensity where the breast is thickest (heel effect). The vertical central ray was also placed near the costal side of the breast in order not to geometrically exclude posterior superior breast tissue from the image field.' [41]

In 1978, meticulously designed mammographic grids were introduced that increased 'image contrast by reducing the amount of scattered radiation reaching the image receptor particularly in dense fibroglandular breasts and thicker breasts.' ${ }^{[41,47]}$. These grids are not similar to the ones generally used in radiology ${ }^{[41,48,49]}$. For these to function, certain criteria must be met:

1) For image preservation purposes, the grids must be as thin as possible

2) The grids must have 'low-density interspace material that is compatible with low-kVp Radiation'

3) In addition, the grids must be mobile so that they may make the gridlines as close to impossible to invisible. ${ }^{[41]}$

In 1981, The very first pivoting molybdenum anode joining both an enormous central spot for routine pictures and a little central spot for amplified pictures' ${ }^{[41,50]}$

The American College of Radiology Mammography Accreditation Program first came to be in $1987^{\text {[41] }}$. Today, according to the College's website ${ }^{[51]}$, the requirements for accreditation are multifactorial. We believe the criteria listed is rather logical and befitting the seriousness of the issue at hand.

Although all the aforementioned projects clearly indicate the possibility of mammograms being used for breast cancer screening, it seems as if (according to our research) that it was only in the early 1960s that a large-scale screening took place ${ }^{[41]}$. In 1962 Egan ${ }^{[41,52]}$ published a report which illustrated findings of "occult carcinoma" in 53 of 2,000 mammographs carried out indicating the usefulness of the technique and trailblazing what has now been deemed 'mainstream'.

Magnetic Resonance Angiography (MRA): Overview and clinical applications

Given how the technologies between MRI and MRAs overlap in a rather common manner, we have decided it only appropriate to illustrate the differences here. In other words, MRIs and MRAs are the same tests using different technologies. For our purposes, we will be using the MRA categorization illustrated in Carr and Carroll's 'Magnetic Resonance Angiography: Principles and Applications' ${ }^{[53]}$, those being:

1) Contrast-enhanced

$$
\text { 2) } \mathrm{TOF}
$$

3) Phase-contrast, and
4) Steady-state 


\section{Contrast-Enhanced MRA:}

Henceforth referred to as CE-MRA, is, as the name suggests, an MRA conducted with the use of contrast for purposes of clarifying pathology. According to the authors of the aforementioned book:

'Contrast-enhanced MRA techniques achieve signal differences between blood and stationary tissues by manipulating the magnitude of the magnetization, such that the magnitude of the magnetization from moving blood is larger than the magnitude of the magnetization from stationary tissues. Manipulating the magnetization to produce signal differences in CE-MRA techniques is achieved not only by employing the appropriate imaging sequence parameters, but also by injecting a contrast material intravenously to selectively shorten the $\mathrm{T} 1$ of the blood. By implementing a T 1 - weighted imaging method, appropriately synchronized to acquire data during the first pass of the contrast material through the arteries of interest, images can be acquired that show arteries with striking contrast relative to surrounding stationary tissues and veins.' ${ }^{[53]}$

A logical follow-up question that probably manifests itself at this point would be 'what media is used for CEMRAs?'; the answer to that would be 'gadolinium-based contrast materials' ${ }^{[53]}$. In words of the authors of a 2007 article 'Optimizing contrast enhanced MRA (CE MRA), however, requires understanding the complex interplay between Gd injection timing, the Fourier mapping of 3D MR data acquisition and a multitude of parameters determining resolution, anatomic coverage, and sensitivity to motion artifacts. It is critical to time the bolus peak to coincide with central k-space data acquisition, which dominates image contrast.' ${ }^{[54]}$.

According to the authors of the aforementioned book in regards to the imaging sequence of CE-MRA:

'CE-MRA typically is performed using a three-dimensional, RF-spoiled, fast gradient-echo imaging sequence.

The pulse sequence timing diagram looks like the one shown in Fig. 1.16 [page 14 of the book], with the addition of a phase-encoding gradient on the slice-selection axis. Also RF spoiling is used to eliminate, or spoil, the transverse magnetization so it does not contribute to signal in subsequent TR intervals.' [53]

\section{TOF MRA:}

Time-of-flight MRA (henceforth referred to TOF MRA), according to Carroll and Carr 'derive contrast between flowing blood and stationary tissues by manipulating the magnitude of the magnetization, such that the magnetization is large for moving blood and small for stationary tissues' ${ }^{[53]}$. As far as we have been able to conclude, this is where the similarities between TOF MRA and CE-MRA come to an end. The primary difference between the two techniques is that TOF MRA functions while eliminating the need for contrast material injection as it utilizes motion as its source for contrast (blood is in motion; stationary tissues are not) ${ }^{[53]}$. This means that the blood results in a large signal, whilst the stationary tissues result in a smaller signal ${ }^{[53]}$, ergo creating a situation in which both could be differentiated.

In so far as image sequencing is concerned, this is how the authors of the aforementioned book articulated the process:

'TOF methods can be implemented using two-dimensional or three-dimensional acquisition. For both acquisition methods, a spoiled, fast gradient-echo sequence is used. For two dimensional acquisition, thin slices are imaged, 
For three-dimensional acquisition, thin slabs are imaged and the slabs are encoded into slices using a phaseencoding method.

TOF sequences often employ additional gradients on the slice-selection and frequency- encoding axes to refocus unwanted phase accumulations accrued by spins that are in motion during the application of these imaging gradients. These additional gradients typically are referred to as flow-compensation gradients, velocity-compensation gradients, or first-moment-nulling gradients

They serve to reduce signal loss caused by intravoxel dephasing of spins traveling at different velocities.

When a spoiled, fast gradient-echo sequence is used, the signal from tissues decreases with exposure to an increasing number of RF pulses.' ${ }^{[53]}$

So, how is a Two-Dimensional TOF MRA acquired?

1) A number of slices are 'stacked' along the vessel's anatomy

2) Data are acquired from these slices ${ }^{[53]}$

3) The data is interpreted and a report is made

Given the methodology by which the data for two-dimensional TOF MRA is acquired, it is most appropriate for straight blood vessels (e.g.: the carotid arteries) ${ }^{[33]}$. According to the authors of the aforementioned book:

'With 2D TOF MRA, the spoiled, fast gradient-echo method is prescribed so that thin slices $(1-3 \mathrm{~mm})$, oriented perpendicular to the long axis of the vessels of interest are imaged. Prescribing the slices in this manner increases the likelihood that the blood will experience only a very few radiofrequency excitation pulses as it flows through the image slice. When thin slices are imaged, a moderately large tip angle $\left(60^{\circ}\right)$ can be used to suppress the signal from the stationary tissues without substantially suppressing the signal from blood that quickly moves through the image plane. Even when thin slices are imaged, the moderately large tip angle can cause saturation of the signal from slowly moving blood, such as that in the carotid bulb. The degree of saturation can be reduced by decreasing the tip angle and/or increasing the TR of the imaging sequence; however, it must be realized that this also will increase the amount of signal from stationary tissues. Increasing the TR also will lead to a longer scan time.' ${ }^{53}$

As for 3-Dimensional TOF MRAs, the following takes place:

'a slab, oriented perpendicular to the long axis of the vessels of interest, is imaged and the slab is encoded into thin slices using a phase-encoding method. Because a slab is imaged, a small tip angle $\left(30^{\circ}\right)$ must be used so the signal from blood that remains in the slab does not become too saturated. The small tip angle necessary to preserve signal from blood also leads to an undesirable preservation of signal from stationary tissues.' [53]

In summary, these are a few of the differences between two-dimensional and three-dimensional TOF MRAs 
(simply referred to as 2-D and 3-D in the table below; respectively). ${ }^{[3,55]}$

Table 1. Differences between 2-D and 3-D TOF MRAs

\begin{tabular}{|c|c|}
\hline 2-D & 3-D \\
\hline Good sensitivity to slow flow & Bad sensitivity to slow flow \\
\hline Coverage area is relatively large (expandable) & Covers a relatively small area \\
\hline Shorter imaging times & Longer imaging times \\
\hline Best for longer vessels & Best for shorter vessels \\
\hline
\end{tabular}

\section{Phase-contrast MRA}

Henceforth referred to as PC MRAs, are MRA methods which 'provide a direct quantitative measure of the velocity of the flowing blood' ${ }^{[53]}$. These, similar to TOF MRAs, can be attained using 2-D or 3-D image acquiring modalities ${ }^{[53]}$. The 2-D attainments can be relatively rapid in nature which makes them further suitable for cardiac applications (assessment of blood flow throughout the cardiac cycle) ${ }^{[53]}$. As a matter of fact, this is what the authors of a 2014 said regarding the use of 2-D imaging in cardiovascular clinical scenarios:

'Since its original description in the 1980s, phase contrast (PC) magnetic resonance imaging (MRI) has seen broad clinical acceptance for the visualization and quantitative evaluation of blood flow in the heart, aorta and large vessels.' [55]

According to Carr and Carroll:

'Phase-contrast MRA techniques derive contrast between flowing blood and stationary tissues by manipulating the phase of the magnetization, such that the phase of the magnetization is zero for stationary tissues and non-zero for moving tissues.' [53]

The images acquired using this methodology are processed in 3 primary manners. Those being:

1) Phase-difference processing,

2) Complex-difference processing, and

3) Magnitude processing.

More modernly, 4-D flow MRI technology has become further manifest and a topic of discussion. According to a 2014 paper,

'In 4D flow MRI, velocity is encoded along all three spatial dimensions throughout the cardiac cycle, thus providing a time-resolved 3D velocity field.

As for 2D CINE PC-MRI, data acquisition is synchronized with the cardiac cycle and data collection is distributed over multiple cardiac cycles using so called ' $k$-space segmentation' techniques (only a fraction of the entire 4D flow data is measured during each cardiac cycle, the data is successively collected over multiple

RR-intervals). After completion of the 4D flow acquisition, four time-resolved (CINE) 3D datasets are generated ('magnitude' data depicting anatomy and three flow datasets representing velocities ' $\mathrm{Vx}, \mathrm{Vy}$, and 


$$
\text { Vz').' }{ }^{[55]}
$$

Depending on the contributing factors, scans may take 5-20 minutes. In many clinical scenarios, time is of the essence, and these few minutes can mean life or death. Sometimes, clinicians will combine radial data sampling with undersampling to save time ${ }^{[55]}$.

\section{Steady-state MRA}

Alternatively, balanced steady-state free precession (henceforth referred to as bSSFP) imaging techniques are used to preform MRAs ${ }^{[53]}$. According to Carr and Carroll:

'In bSSFP imaging, both the longitudinal and transverse components of magnetization are maintained in a steady-state condition. In order to ensure that the transverse component of magnetization is not spoiled, all of the imaging gradients must be completely balanced so that the net phase accumulation imparted to the spins from one TR to the next is zero.' [53]

In addition, this is what the authors of a 2013 paper commented on the topic:

A common feature of rapid SSFP sequences (whether balanced or not) is their mixed T1 and T2 contrast given by $1=2 \mathrm{M} 0(\mathrm{~T} 2 / \mathrm{T} 1) 1=2$. Unfortunately, the $\mathrm{T} 2 / \mathrm{T} 1-$ weighted contrast is not optimal for diagnostic purposes.' [56]

Conclusion:

In conclusion, radiology is a rather unique and beautiful synchronicity between physics and medicine. This combination, first manifest by the works of W.C Röentgen, is of extreme importance and has saved uncountable lives. We believe this paper was a necessary shining forth of the beauty and unfathomable complexity of this combination. In short, it is a miracle.

Recommendations:

1) The repetition of papers similar to this one every few decades so as to clearly document the evolution of this science

2) This evolution (and future works) becoming a compulsory part of medical education worldwide

Acknowledgements:

The authors would like to thank Napata College's Departments of psychiatry and radiology as well Napata Research and Innovation Center (NRIC) and the logistical staff for all their support.

Abbreviations (in alphabetical order):

ACS = Acute Coronary Syndrome

$\mathrm{CT}=$ Computed Tomography

CTA = Computed Tomography Angiography 
CE-MRA = Contrast-enhanced Magnetic Resonance Angiography

MSCT = Multi-slice Spiral Computed Tomography

SPECT $=$ Single Photon Emission Computed Tomography

US = Ultrasound

GEP $=$ Gastro-enteropancreatic

$\mathrm{MHz}=$ Megacycles per second

MRA = Magnetic Resonance Angiography

MIT = Massachusetts Institute of Technology

MRI = Magnetic Resonance Imaging

NMR = Nuclear Magnetic Resonance

SUNY $=$ State University of New York

TOF $=$ Time-of-Flight

References:

1) Dunn PM. Wilhelm Conrad Röentgen (1845-1923), the discovery of $x$ rays and perinatal diagnosis. Arch Dis Child Fetal Neonatal Ed 2001;84:F138-F139

2) Assmus A. Early History of X Rays. Beam Line. 1995. 10-24

3) Graham H. X-rays and radium. In: Eternal Eve. London: Heinemann, 1950:574-609.

4) Nüsslin F. Wilhelm Conrad R*ontgen: The scientist and his discovery. Physica Medica 79 (2020) 65-68. https://doi.org/10.1016/j.ejmp.2020.10.010

5) Kalender WA. Technical foundations of spiral CT. Semin Ultrasound CT MR 1994; 15:81-89.

6) Fuchs T., Kachelrie M., Kalender WA. Technical advances in multi-slice spiral CT. European Journal of Radiology 36 (2000) 69-73

7) Wang X., Zhang Y., et. al. Diagnosis value of multi-slice spiral CT. Journal of X-Ray Science and Technology 24 (2016) 649-655 DOI 10.3233/XST-160585

8) Goldstein JA. Coronary CT Angiography Identification of Patients and Plaques “At Risk". .JACC. V O L . 71 , NO . 22, $2018.2523-2526$

9) Sun Z, Choo GH, Ng KH. Coronary CT Angiography: current status and continuing challenges. The British Journal of Radiology, 85 (2012), 495-510. DOI: 10.1259/bjr/15296170

10) Mariani G, et. al. A review on the clinical uses of SPECT/CT. Eur J Nucl Med Mol Imaging (2010) 37:1959-1985. DOI 10.1007/s00259-010-1390-8

11) Rogalla P. Kloeters C. Hein PA. CT Technology Overview: 64-Slice and Beyond. Radiol Clin N Am 47 (2009) 1-11 doi:10.1016/j.rcl.2008.10.004

12) Duck F. ULTRASOUND - THE FIRST FIFTY YEARS. MEDICAL PHYSICS INTERNATIONAL Journal, Special Issue, History of Medical Physics 5, 2021. 470-498

13) Pickover CA. From Witch Doctors to Robot Surgeons, 250 Milestones in the History of Medicine. Sterling Publishing Co., Inc. 2013

14) Duddell W. On rapid variations in the current through the direct-current arc. J Inst Elec Eng 1901;30:232-267.

15) Altberg W. Über kurze akustische Wellen bei Funkentladungen von Kondensatorem. Ann der Physik (4) $1907 ; 23: 267-276$.

16) Pohlman VR, Richter R, Parow E. Uber die Ausbreitung und Absorption des Ultraschalls im menschlichen Gewebe und seine therapeutische Wirkung an Ischias und Plexusneuralgie. DEUTSCHE MEDIZINISCHE WOCHENSCHRIFT. 17. Februar 1939. 251-254. (In German)

17) Dognon A. Les ultrasons et leurs applications. Ch 5:Transmissions et exploration par ultrasons. Paris. Presses Universitaires de France. 1953. 
18) Campbell S. A Short History of Sonography in Obstetrics and Gynaecology. FVV in ObGyn, 2013,5 (3): 213-229.

19) Gottesfeld KR, Thompson KE, Holmes JH et al. Ultrasonic placentography-a new method for placental localisation. Am J Obstet Gynec. 1966;96:538-47.

20) Donald I, Abdulla U. Placentography by sonar. J Obstet Gynaecol Br Commonw. 1968;75:993-1006.

21) Sunden B. PLACENTOGRAPHY BY ULTRASOUND. Acta Obstet Gynec Scand 49: 179-184, 1970

22) Campbell S, Johnstone FD, Holt EM et al. Anencephaly: early ultrasonic diagnosis and active management. Lancet. 1972; 2(7789):1226-7.

23) Campbell S. Early prenatal diagnosis of neural tube defects by ultrasound. Clin Obstet Gynecol. 1977;20:351-9.

24) Hobbins JC, Grannum PA, Berkowitz RL et al. Ultrasound in the diagnosis of congenital anomalies. Am J Obstet Gynecol. 1979;134:331-45.

25) Macchia RJ, Termine JE, Buchen CD. Raymond V. Damadian, M.D.: Magnetic Resonance Imaging and the Controversy of the 2003 Nobel Prize in Physiology or Medicine. THE JOURNAL OF UROLOGY. Vol. 178, 783-785, September 2007. 783-785. DOI:10.1016/j.juro.2007.05.019

26) Mattson J and Simon M: The Pioneers of NMR and Magnetic Resonance in Medicine: The Story of MRI. Jericho, New York: Bar-Ilan University Press 1996; p 655.

27) Mattson J and Simon M: The Pioneers of NMR and Magnetic Resonance in Medicine: The Story of MRI. Jericho, New York: Bar-Ilan University Press 1996; p 613.

28) https://lemelson.mit.edu/resources/raymond-damadian. Accessed on the $16^{\text {th }}$ of March 2021

29) Heggie J.C.P. Technical developments in radiology in Australasia dating from 1977. Australas. Phys. Eng. Sci. Med. Vol. 30, No 3, 2007. 160-177

30) Mansfield, P. and Maudsley, A.A., Line scan proton spin imaging in biological structures by NMR, Phys. Med. Biol., 21: 847-852, 1976

31) Damadian, R., Goldsmith, M. and Minkoff, L., NMR in cancer: XVI. Fonar image of the live human body, Physiol. Chem. Phys., 9: 97-100, 1977.

32) Mattson J and Simon M: The Pioneers of NMR and Magnetic Resonance in Medicine: The Story of MRI. Jericho, New York: Bar-Ilan University Press 1996.

33) Lauterbur P.C. Image Formation by Induced Local Interactions: Examples Employing Nuclear Magnetic Resonance. 1973. Nature Vol. 242 MARCH 16 1973. 190-191

34) Kauffman G. Nobel Prize for MRI Imaging Denied to Raymond V. Damadian a Decade Ago. Chem. Educator 2014, 19, 73-90. 10.1333/s00897142540a

35) Lagerkvist, U; Norrby, E. The Periodic Table and a Missed Nobel Prize; World Scientific Publishing Co.: Singapore/Hackensack, NJ/London, 2012; p 114.

36) Kauffman, G. B. 2003 Nobel Prize for MRI denied to Raymond V. Damadian. The Collegian at Fresno State, October 20, 2013. http://collegian.csufresno.edu/2013/10/20/2003-nobel-prize-formridenied-to-raymond-v-damadian (accessed November 2013).

37) Kauffman, G. B. 2003 Nobel Prize for MRI Denied to Raymond Vahan Damadian. Armenian Weekly, November 7, 2013. http://www.armenianweekly.com/2013/11/07/2003-nobel-prize-formridenied-to-raymond-vahan-damadian (accessed November 2013).

38) Isidore Isaac Rabi. http://en.wikipedia.org/wiki/Isidor_Isaac_Rabi; The Nobel Prize in Physics 1944. Isidor Isaac Rabi-Biographical. http://www.nobelprize.org/nobel_prizes/physics/laureates/1944/rabibio.html (accessed November 2013).

39) Bryon MacWilliams. Russian claims first in magnetic imaging. NATURE|VOL 426 | 27 NOVEMBER 2003|www.nature.com/nature. 375 
40) Dill T. Contraindications to magnetic resonance imaging. Heart 2008;94:943-948. doi:10.1136/hrt.2007.125039. 943-948

41) Feig SA. Mammographic Screening: An Historical Perspective. Seminars in Roentgenology, Vol XXVIII, No 3 (July), 1993: pp 193-203

42) Warren SL: A roentgenologic study of the breast. AIR 24:113-124, 1930

43) Gershon-Cohen J, StricklerA: Roentgenologic examination of the normal breast: Its evaluation in demonstrating early neoplastic changes, A JR 40:189-201, 1938

44) Ingleby H, Gershon-Cohen J: Comparative Anatomy, Pathology, and Roentgenology of the Breast. Philadelphia, PA, University of Pennsylvania Press, 1960

45) Egan R: Experience with mammograpby in a tumor institution: Evaluation of 1,000 cases. AIR 75:894-900, 1960

46) Lundgren B: The oblique view at mammography. Br J Radio150:626-628, 1976

47) Friedrich M, Weskamp P: New modalities in mammographic imaging: Comparison of grid and air gap magnification techniques. Medicamundi 23:1-16, 1978

48) National Council on Radiation Protection and Measurements Scientific Committee No. 72: Mammography-A User's guide (NCRP Report No. 85). Bethesda, MD, National Council on Radiation Protection and Measurements, 1986

49) American Association of Physicists in Medicine, Task Group No. 7, Diagnostic X-ray Imaging: Equipment Requirements and Quality Control for Mammography (AAPM Report No. 29). New York, NY, American Institute of Physics, 1990

50) Gabbay E: Mammography x-ray sources, in Haus AG, Yaffe MJ (eds): Syllabus: A Categorical Course in Physics Technical Aspects of Breast Imaging. Oak Brook, IL, Radiological Society of North America, 1992, pp 43-58

51) https://accreditationsupport.acr.org/support/solutions/articles/11000063274-complete-accreditationinformation-mammography (accessed on the 29th of March 2021)

52) Egan RL: Fifty-three cases of carcinoma of the breast, occult until mammography. AJR 88:10951111,1962

53) Carr J, Carroll T. Magnetic resonance angiography. New York: Springer Science+Business Media, LLC; 2012.

54) Zhang H., et. al. 2007. 3D Contrast-Enhanced MR Angiography. J. Magn. Reson. Imaging 2007;25:13-25.

55) Stankovic Z, Allen BD, Garcia J, Jarvis KB, Markl M. 4D flow imaging with MRI. Cardiovasc Diagn Ther 2014;4(2):173-192. doi: 10.3978/j.issn.2223-3652.2014.01.02

56) Bieri O, Scheffler K. Fundamentals of Balanced Steady State Free Precession MRI. JOURNAL OF MAGNETIC RESONANCE IMAGING 38:2-11 (2013) VC 2013. DOI 10.1002/jmri.24163 